\title{
Effects of dietary intake patterns from 1 to 4 years on BMI $z$-score and body shape at age of 6 years: a prospective birth cohort study from Brazil
}

\author{
Leonardo Pozza Santos ${ }^{1,2}$ [ $\cdot$ Ken K. Ong ${ }^{3} \cdot$ Ina S. Santos ${ }^{1} \cdot$ Alicia Matijasevich $^{1,4} \cdot$ Aluísio J. D. Barros $^{1}$
}

Received: 9 November 2017 / Accepted: 13 May 2018 / Published online: 17 May 2018

(c) The Author(s) 2018

\begin{abstract}
Purpose To assess the association between dietary intake patterns from 1 to 4 years and BMI and body shape at age of 6 years.

Methods This longitudinal study was based on 3374 Brazilian children from the 2004 Pelotas Birth Cohort Study. We used previously described dietary patterns from 1 to 4 years as the main exposure. We defined body shape using scores for corpulence (a recently described body shape component measured by Photonic Scanner), and trunk and gynoid fat mass percentage from DXA. We run linear regression models to evaluate the associations between dietary patterns from 1 to 4 years and BMI and body shape at 6 years.

Results Several apparent associations between dietary patterns and BMI or body shape were explained by sociodemographic factors. High adherence to snacks (positive loadings to coffee, bread and cookies) at 4 years predicted lower BMI, but higher gynoid fat mass percentage at 6 years, while higher adherence to staple at 2 years (positive loadings to rice and beans) predicted higher trunk fat mass and lower gynoid fat mass. Finally, higher scores on milks at 1 year (positive loading to breast milk) predicted higher gynoid fat mass at 6 years.

Conclusion There were inconsistent associations between dietary patterns in infancy and early childhood and BMI and body shape at 6 years. In adjusted analyses, higher adherence to breast milk at 1 year and to snacks at 4 years appeared to be beneficial for body shape, associated with lower BMI, but higher peripheral fat.
\end{abstract}

Keywords Diet $\cdot$ Food intake $\cdot$ Body mass index $\cdot$ Body shape

\section{Introduction}

Latin American countries faced nutrition transition in the recent years, where a 'traditional' diet has been replaced by a more 'Westernized' diet, impacting on obesity rates [1-3]. Recent estimates showed that, in Latin America, more than 20 million of children aged $0-19$ years are overweight or

Electronic supplementary material The online version of this article (https://doi.org/10.1007/s00394-018-1720-3) contains supplementary material, which is available to authorized users.

Leonardo Pozza Santos

leonardo_pozza@yahoo.com.br

Ken K. Ong

ken.ong@mrc-epid.cam.ac.uk

Ina S. Santos

inasantos@uol.com.br

Alicia Matijasevich

amatija@yahoo.com

Aluísio J. D. Barros

abarros.epi@gmail.com
1 Post-graduate Program in Epidemiology, Federal University of Pelotas, Pelotas, Brazil

2 Nutrition School, Federal University of Pampa, Luiz Joaquim de Sá Britto, s/n, Itaqui 97650-000, Brazil

3 Medical Research Council (MRC) Epidemiology Unit, Institute of Metabolic Science, Cambridge, UK

4 Department of Preventive Medicine, Faculty of Medicine FMUSP, University of São Paulo, São Paulo, Brazil 
obese, representing 20-25\% of the overall children population [4]. Specifically in Brazil, more than $1 / 3$ of children are overweight or obese according to recent estimates [5].

Obesity status may be affected by the type of food consumed in childhood as well as by the interaction among food components [6, 7]. However, it is a challenge measuring food and nutrient intake in childhood, and principal component analysis (PCA) has emerged as a useful tool to assess dietary intake patterns, summarizing predominant models of intake $[8,9]$. Some evidences have suggested that dietary intake patterns are stable since the early ages [10-12], but the effect of dietary intake patterns on obesity status and adiposity is quite inconsistent [13-15].

The majority of papers assessing the association between dietary intake patterns and adiposity has been conducted in high-income countries and has used body mass index (BMI) as the main outcome. As BMI has inherent limitations, such as do not distinguish fat mass from fat-free mass and do not allow to assess body fat distribution, new alternatives to measure body composition and body shape have arisen in last years [16, 17]. More recently, the three-dimensional photonic scanner (3DPS) has been used as a new alternative to measure body shape and size in different populations. This equipment projects lights on the body surface and read it back, and computer algorithms create a 3D body image of the surface. A specialized software uses this 3D image to calculate several body measures such as girths, lengths, areas, and volumes. When measuring waist circumference, the 3DPS-generated measures were greater, but showed high correlation and ranking consistency in children and adults when compared to tape-based measures [18, 19]. This approach was used in the 6-year-old follow-up of the 2004 Pelotas Birth Cohort Study to describe the components of body shape and size of children [20].

We have previously identified and described dietary intake patterns in infancy ( 1 and 2 years) and early childhood (4 years) [21], and also body shape and size at 6 years. Here, we describe the relationship between those early life dietary intake patterns and BMI $z$-score and body shape at 6 years in this population-based sample from Brazil.

\section{Methods}

\section{Subjects}

Pelotas is a municipality with around 340,000 inhabitants situated in southern Brazil. Currently, four birth cohort studies are being followed up at regular intervals (the 1982, the 1993, the 2004, and the 2015 Pelotas Birth Cohort Studies), including newborns from mothers residing in the city's urban area. Specifically for this study, we used data from the 2004 Pelotas Birth Cohort Study, since information about dietary intake patterns from 1 to 4 years of age as well as body shape components at 6 years are only available for this cohort.

In 2004, 99.2\% (4231) of all babies born from mothers living in the urban area were recruited to take part of the 2004 Pelotas Birth Cohort Study. In the first $24 \mathrm{~h}$ after birth, the interviewers recruited and interviewed mothers, and evaluated the newborns at maternity hospitals. They collected information about family, maternal characteristics, the current pregnancy, and delivery. Children were also followed at ages of 3 months, and 1, 2, 4, and 6 years, with followup rates of 95.7, 94.2, 93.4, 91.8, and 90.2\%, respectively. Details of all follow-ups were reported previously [22, 23]. The Research Ethic Committee of the Medical School from the Federal University of Pelotas approved all follow-up waves of the study; each time, the children's legal guardians gave their written informed consent to participate in the study.

\section{Dietary intake}

Children's dietary intake during the 24-h prior to interviews at ages 1,2 , and 4 years was assessed by a questionnaire completed by the child's mother. The questionnaires used in 1-, 2-, and 4-year-old follow-ups asked mothers to report whether each food item from a list had been consumed during meals or periods of the day (breakfast, morning, lunch, afternoon, dinner, evening, and night), but they do not allow to quantify the amount of foods consumed at each period of the day. This list of commonly consumed food items was constructed based on children's food intake collected in a multicentre study conducted in Pelotas (WHO Multicentre Growth Reference Study in Brazil) [24].

Dietary intake patterns at 1,2 , and 4 years were identified by PCA and previously described by Gatica et al. [21]. Each dietary pattern comprises food items with positive or negative loadings. Five components were identified at each age; four of them similar in all time points, as described below.

Five dietary patterns were identified at ages 1 and 2 years:

- Milks (positive loading for breast milk; negative loading for cow's milk);

- Staple (positive loading for rice and beans; negative loading for pasta);

- Beverages (positive loading for juice; negative loading for water and tea);

- Snacks [positive loading for coffee, bread and cookies; negative loading for fruits (1 year) or yogurt (2 years)];

- Meat and vegetables [positive loading for meats, vegetable and legumes, potato and cassava, and fruits (only 2 years)]. 
At age 4 years, child diets comprised five slightly different patterns:

- Milks (positive loading for cow's milk and chocolate powder);

- Staple (positive loading for rice, beans, and meat);

- Beverages (positive loading for juice; negative loading for soft drinks);

- Snacks (positive loading for coffee, bread and cookies, and water and tea; negative loading for yogurt and soft drinks);

- Treats (positive loading for crisps, sweets, and chocolate).

Supplementary table 1 shows details about dietary intake patterns at the three age-points, including all food items with positive and negative loadings of each component.

\section{Body mass index and body shape}

The 6-year-old follow-up of the 2004 Pelotas birth cohort study occurred between 2010 and 2011 and followed up
$70 \%$ of the variance in children's body shape and size, and was the only one which was correlated with the traditional anthropometric (weight, BMI, waist circumference, and height) and body composition measures (fat, lean and bone mass, and trunk, android, and gynoid fat mass) (Pearson's correlation $>0.70$ ). Briefly, corpulence included positive loadings for measures of body circumferences (waist, hip, seat, chest, abdomen, knee, calf, and biceps circumferences), diameters (sagittal diameter, waist, and abdomen width), and volumes (body volume and torso volume) [20].

As corpulence is a relatively novel approach to define body shape, we also used central and peripheral fat mass measures as additional body shape definitions, to facilitate interpretation of the findings. We assessed regional fat mass using dual-energy X-ray absorptiometry (DXA) (GE Lunar Prodigy densitometer). Specific trained field workers collected DXA scans following the manufacturer's recommendations and position protocols. We used trunk and gynoid fat mass percentage from DXA as measures of central and peripheral body shape, respectively. Trunk and gynoid fat mass percentage were defined as follows:

Trunk fat mass percentage $=($ trunk fat mass $(\mathrm{kg}) /$ total fat mass $(\mathrm{kg})] \times 100$.

Gynoid fat mass percentage $=[$ gynoid fat mass $(\mathrm{kg}) /$ total fat mass $(\mathrm{kg})] \times 100$.

3722 children. In this follow-up, weight was measured by a high precision scale $(0.01 \mathrm{~kg})$ linked to BodPod machine (Cosmed, Italy, http://goo.gl/7jzfLc). Height was measured twice by trained field workers using a Harpenden metal stadiometer, with 1-mm precision (Holtain, Crymych, $\mathrm{UK})$. BMI was then calculated by dividing weight $(\mathrm{kg})$ by height $(\mathrm{m})$ squared and standardized by age and sex using the World Health Organization (WHO) 2007 growth reference [25] for 3374 children who had available information about weight and height. The field workers who conducted anthropometric measures were standardized according to the Habitch criteria [26].

Body shape was assessed using $\mathrm{TC}^{2}$ Three-Dimensional Photonic Scanner (North Carolina, USA; http://www.tc2. com). Two photonic scans were performed in each child, capturing 38 measurements among circumferences, lengths, volumes, and surface areas. If the difference in waist circumference was greater than $10 \mathrm{~mm}$, a third scan was performed, and arithmetic mean of those two measurements with difference lower than $10 \mathrm{~mm}$ was calculated. Specially trained field workers carried out all photonic scans and the machine was calibrated in the beginning of each working day.

Particularly relevant for our study, we defined body shape according to the components of body shape and size at 6 years described by Santos et al. [20]. We used the major component called corpulence, which explained almost

\section{Socioeconomic and demographic information}

Socioeconomic position (SEP) was measured according to the Brazilian National Wealth Index (IEN). Briefly, this index considers household assets and the household head's education according to Brazilian Demographic Census data [27]. We also used information about maternal schooling (years of formal education), number of children at the time of birth, maternal age at birth, maternal smoking during pregnancy, child's sex and skin colour, birth weight, exclusive breastfeeding duration, and number of meals per day at 1,2 , and 4 years of age. All the details about data collection of socioeconomic and demographic variables were reported previously [22].

\section{Statistical analysis}

To analyze dietary patterns, we categorized the scores of each dietary intake component at 1,2 , and 4 years into tertiles, representing low (first tertile), intermediate (second tertile), and high scores (third tertile). Scores for corpulence were standardized providing a mean of 0 and standard deviation 1. Associations between dietary patterns at 1,2, and 4 years and BMI $z$-score or corpulence at 6 years were assessed using multiple linear regression separately by each age-point. 
We performed crude (Supplementary tables 2, 3) and adjusted analyses, considering as potential confounders those variables which were associated $(p$ value $\leq 0.2)$ with at least one exposure and one outcome, to keep the same model for all the analyses tested in the study. All associations were adjusted for socioeconomic position, number of siblings, maternal age at birth and education, smoking during pregnancy, child's sex and skin colour, birth weight, exclusive breastfeeding duration, and number of meals per day.

We conducted additional analyses using regional measures of body shape from DXA (trunk and gynoid fat mass percentage). As both BMI and corpulence were standardized, we also standardized values for trunk and gynoid fat mass percentage to keep the same unity for all outcomes. Furthermore, we performed here the same adjustment used for BMI and corpulence.

We evaluated dietary patterns separately by each agepoint (1, 2, and 4 years), since their food item loadings varied slightly by age, and there were weak inter-correlations between components (Pearson's correlation $\leq 0.50$ ), making it difficult to combine components across ages. Nonetheless, dietary components at the previous age were always associated with similar-labeled components at next age ( $p$ value $\mathrm{s}<0.20$ ), despite weak correlations among them (unpublished results). Then, when the main exposure was dietary intake patterns at 2 and 4 years, we also adjusted for similarlabeled components at the previous age. For example, when the main exposure was milks at 2 years, we included in the model scores of milks at 1 year as a potential confounder. When the main exposure was milks at 4 years, we included scores of milks at 1 and 2 years in the model.

We evaluate whether sex modifies the effect of dietary intake patterns on BMI and body shape using the product term of child's sex and each outcome. In all models, we assessed the variance inflation factor to assess for multicollinearity among independent variables. All analyses were carried out using Stata 13.1 (Stata Corp., College Station, TX, USA).

\section{Results}

We included 3374 children (52\% boys) in the analysis for whom information on BMI at 6 years was available. The mean weight was $25 \mathrm{~kg}( \pm 5 \mathrm{~kg})$ and the mean height was

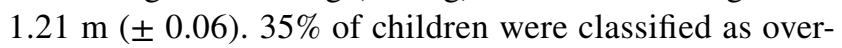
weight or obese according to the WHO 2007 international growth reference. Table 1 presents socioeconomic, maternal, and children's characteristics. Mothers were more likely to have at least 5 years of formal education, at least two children, and were also more likely to age 18-35 years by the time of birth. Children were more likely to be boys and white, and the averaged birth weight of this sample was 3.2 $\mathrm{kg}$ (Table 1). The mean of daily meals decreased from 1 to 4 years (6.3 meals at 1 year, 5.9 at 2 years and 5.2 at 4 years), and adherence to dietary intake components had small effect on the number of meals per day (Supplementary table 4).

Compared to those followed-up at 6 years, children lost to follow-up presented lower SEP, were born to mothers with lower formal education, had more siblings, and presented higher prevalence of low birth weight. There was no difference in maternal age, number of cigarettes per day at pregnancy, child's sex and skin colour, and duration of exclusive breastfeeding (Table 1). It is important to highlight that we did not observe any differences in the adherence of dietary intake patterns at 1,2, and 4 years between children followed at 6 years and those lost to follow-up (data not shown).

Tables 2 and 3 show inconsistent associations between dietary intake patterns at 1,2 , and 4 years and $z$-scores of BMI and corpulence after adjustment for potential confounders included in the model. Milks, staple, meat and vegetables, treats, and beverages at the three age-points were not associated with BMI and corpulence at 6 years. Higher scores on snacks at 4 years independently predicted lower BMI $z$-score at 6 years $(\beta=-0.17 ; 95 \% \mathrm{CI}-0.30$ to -0.03$)$. Higher scores on snacks also predicted lower corpulence at 6 years, but results for this outcome were not significant.

Associations between dietary intake patterns and measures of regional body fatness were also inconsistent after adjustment for confounders. Trunk fat mass percentage was only associated with staple intake at 2 years: high score on staple at 2 years predicted higher trunk fat mass $(\beta=0.10$; 95\% CI 0.01-0.19) (Table 4). Gynoid fat mass percentage was the most associated outcome with dietary intake patterns. High scores of milks at age of 1 were positively associated with $z$-scores of gynoid fat mass percentage $(\beta=0.16$; 95\% CI 0.06-0.27), while high scores on staple at 2 years were negatively associated with gynoid fat mass percentage at 6 years $(\beta=-0.11 ; 95 \% \mathrm{CI}-0.20$ to -0.02$)$. Finally, scoring high on snacks at 4 years predicted higher gynoid fat mass percentage $z$-score at age of 6 years $(\beta=0.17 ; 95 \%$ CI 0.07-0.26), independent of the potential confounders included in the models (Table 5).

\section{Discussion}

Our study in this Brazilian population-based sample showed that there were no consistent associations between dietary intake patterns from 1 to 4 years and BMI and body shape at age of 6 years. The previous studies in different settings have demonstrated no consistent associations between dietary intake patterns and BMI and adiposity in children and adolescents $[14,15,28,29]$. Nonetheless, other investigations have suggested that association between dietary intake and 
Table 1 Socioeconomic, maternal, and children's characteristics

\begin{tabular}{|c|c|c|c|}
\hline Characteristics & Followed-up, $N(\%)$ & Dropped, $N(\%)$ & $p$ value \\
\hline SEP (quintiles) & & & 0.001 \\
\hline First (poorest) & $763(22.7)$ & $262(30.8)$ & \\
\hline Second & $718(21.4)$ & $146(17.2)$ & \\
\hline Third & $763(22.7)$ & $157(18.5)$ & \\
\hline Fourth & $555(16.5)$ & $112(13.2)$ & \\
\hline Fifth (richest) & $561(16.7)$ & $174(20.5)$ & \\
\hline Maternal education (years) & & & 0.002 \\
\hline $0-4$ & $505(15.1)$ & $150(17.8)$ & \\
\hline $5-8$ & $1403(42.0)$ & $328(38.9)$ & \\
\hline$\geq 9$ & $1436(42.9)$ & $366(43.4)$ & \\
\hline Number of children & & & 0.005 \\
\hline 1 & $1345(39.9)$ & $321(37.5)$ & \\
\hline 2 & $895(26.5)$ & $216(25.2)$ & \\
\hline 3 & $546(16.2)$ & $134(15.6)$ & \\
\hline$\geq 4$ & $587(17.4)$ & $186(21.7)$ & \\
\hline Maternal age at birth (years) & & & 0.425 \\
\hline$<18$ & $323(9.6)$ & $73(8.5)$ & \\
\hline $18-35$ & $2687(79.7)$ & $704(82.2)$ & \\
\hline$>35$ & $363(10.8)$ & $79(9.2)$ & \\
\hline Maternal smoking at pregnancy & & & 0.167 \\
\hline No smoking & $2464(74.9)$ & $614(73.3)$ & \\
\hline$<20$ cigarettes/day & $788(24.0)$ & $214(25.5)$ & \\
\hline$\geq 20$ cigarettes/day & $36(1.1)$ & $10(1.2)$ & \\
\hline Children's sex & & & 0.366 \\
\hline Boys & $1739(51.5)$ & $193(57.4)$ & \\
\hline Girls & $1635(48.5)$ & $143(42.6)$ & \\
\hline Children's skin colour (mother's report) & & & 0.392 \\
\hline White & $2249(71.4)$ & $235(74.1)$ & \\
\hline Brown & $487(15.5)$ & $41(12.9)$ & \\
\hline Black & $414(13.1)$ & $41(12.9)$ & \\
\hline Birth weight $(\mathrm{g})$ & & & $<0.001$ \\
\hline$<2500$ & $289(8.6)$ & $120(14.9)$ & \\
\hline$\geq 2500$ & $3085(91.4)$ & $683(85.1)$ & \\
\hline Exclusive breastfeeding duration & & & 0.054 \\
\hline$\leq 7$ days & $844(25.3)$ & $210(30.6)$ & \\
\hline 8 days $-<1$ month & $361(10.8)$ & $81(11.8)$ & \\
\hline $1-2.9$ months & $1203(36.1)$ & $234(34.1)$ & \\
\hline$\geq 3$ months & $924(27.7)$ & $162(23.6)$ & \\
\hline
\end{tabular}

The 2004 Pelotas Cohort Study $(N=3374)$

Maximum percentage of unknown observation: 224 (6.6\%) for children's skin colour SEP socioeconomic position
BMI in children would be better explained by the amount of fat-free mass than fat mass [30, 31]. To test this hypothesis, we performed extra analysis using fat-free mass index from DXA as the outcome, adjusting for the same potential confounders used for the other outcomes. As we observed in supplementary table 5 , there were no associations between dietary intake patterns at 1,2, and 4 years and fat-free mass index at 6 years.
Even with the lack of significance in the majority of associations tested here, our results showed that the dietary component labeled staple at 2 years, and the other one labeled snacks at 4 years were the only ones which remained associated with more than one outcome, despite the effect sizes seen had been small for these associations. High score on staple, characterized by high adherence to rice and beans, the ubiquitous combination in Brazilian diet, was associated 


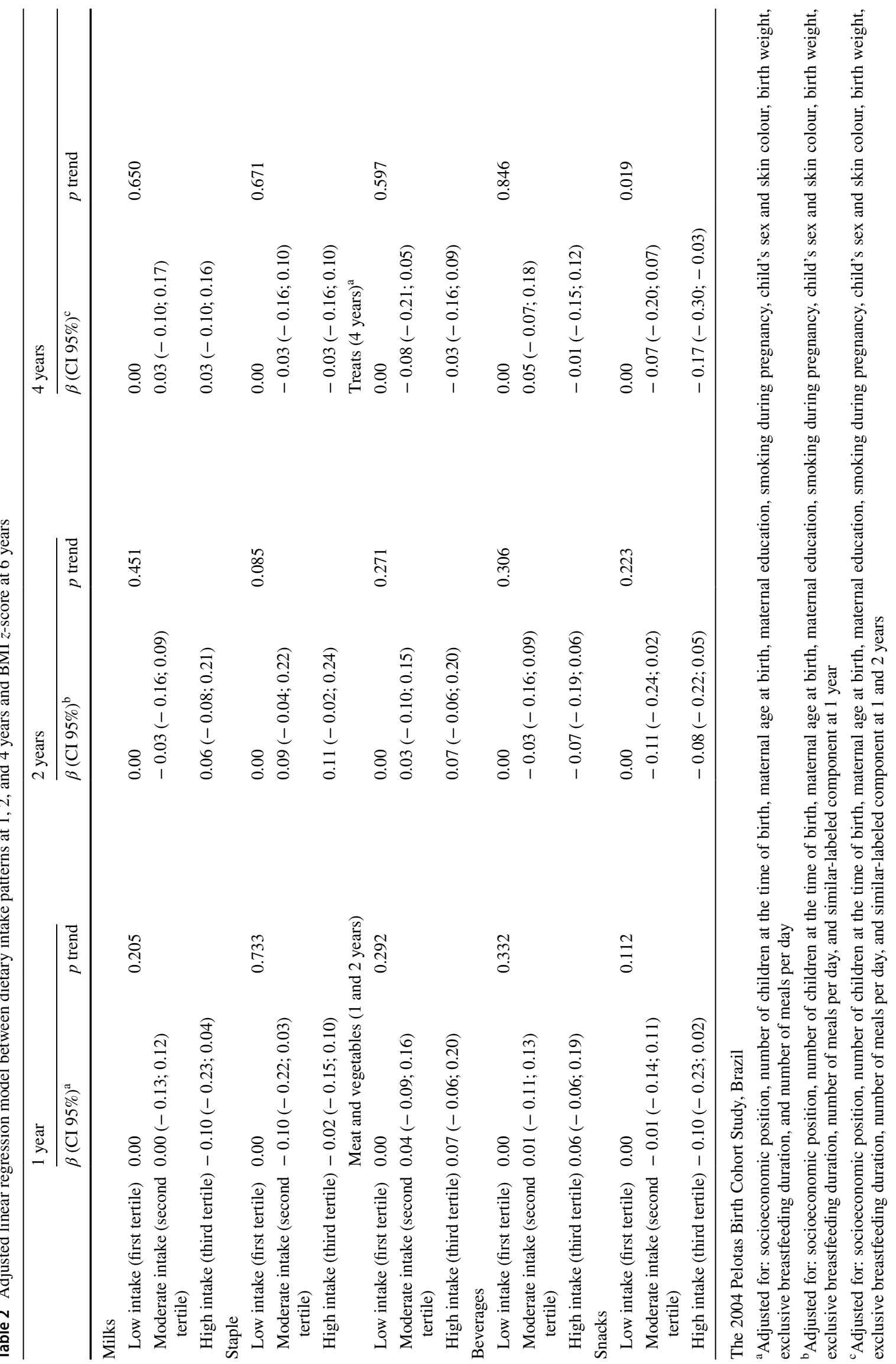


Table 3 Adjusted linear regression model between dietary intake patterns at 1,2 and 4 years and corpulence z-score at 6 years

\begin{tabular}{|c|c|c|c|c|c|c|}
\hline & \multicolumn{2}{|l|}{1 year } & \multicolumn{2}{|l|}{2 years } & \multicolumn{2}{|l|}{4 years } \\
\hline & $\beta(\mathrm{CI} 95 \%)^{\mathrm{a}}$ & $p$ trend & $\beta(\mathrm{CI} 95 \%)^{\mathrm{b}}$ & $p$ trend & $\beta(\mathrm{CI} 95 \%)^{\mathrm{c}}$ & $p$ trend \\
\hline \multicolumn{7}{|l|}{ Milks } \\
\hline Low intake (first tertile) & 0.00 & 0.444 & 0.00 & 0.832 & 0.00 & 0.286 \\
\hline Moderate intake (second tertile) & $-0.02(-0.12 ; 0.07)$ & & $-0.02(-0.11 ; 0.07)$ & & $0.04(-0.06 ; 0.13)$ & \\
\hline High intake (third tertile) & $-0.04(-0.14 ; 0.06)$ & & $0.01(-0.09 ; 0.12)$ & & $0.05(-0.04 ; 0.15)$ & \\
\hline \multicolumn{7}{|l|}{ Staple } \\
\hline Low intake (first tertile) & 0.00 & 0.245 & 0.00 & 0.059 & 0.00 & 0.404 \\
\hline Moderate intake (second tertile) & $-0.10(-0.20 ;-0.01)$ & & $0.04(-0.05 ; 0.13)$ & & $-0.02(-0.08 ; 0.11)$ & \\
\hline \multirow[t]{2}{*}{ High intake (third tertile) } & $-0.06(-0.15 ; 0.04)$ & & $0.09(-0.01 ; 0.18)$ & & $0.04(-0.06 ; 0.14)$ & \\
\hline & \multicolumn{3}{|c|}{ Meat and vegetables ( 1 and 2 years) } & & Treats $^{\mathrm{a}}$ & \\
\hline Low intake (first tertile) & 0.00 & 0.090 & 0.00 & 0.126 & 0.00 & 0.669 \\
\hline Moderate intake (second tertile) & $0.05(-0.04 ; 0.14)$ & & $0.03(-0.06 ; 0.12)$ & & $0.00(-0.10 ; 0.09)$ & \\
\hline High intake (third tertile) & $0.08(-0.01 ; 0.18)$ & & $0.08(-0.02 ; 0.17)$ & & $-0.02(-0.11 ; 0.07)$ & \\
\hline \multicolumn{7}{|l|}{ Beverages } \\
\hline Low intake (first tertile) & 0.00 & 0.489 & 0.00 & 0.539 & 0.00 & 0.537 \\
\hline Moderate intake (second tertile) & $0.04(-0.05 ; 0.13)$ & & $-0.06(-0.15 ; 0.04)$ & & $0.03(-0.06 ; 0.13)$ & \\
\hline High intake (third tertile) & $0.03(-0.06 ; 0.12)$ & & $-0.03(-0.13 ; 0.06)$ & & $0.03(-0.07 ; 0.13)$ & \\
\hline \multicolumn{7}{|l|}{ Snacks } \\
\hline Low intake (first tertile) & 0.00 & 0.046 & 0.00 & 0.306 & 0.00 & 0.077 \\
\hline Moderate intake (second tertile) & $0.02(-0.07 ; 0.11)$ & & $-0.06(-0.15 ; 0.04)$ & & $-0.07(-0.16 ; 0.03)$ & \\
\hline High intake (third tertile) & $-0.09(-0.19 ; 0.00)$ & & $-0.05(-0.15 ; 0.05)$ & & $-0.09(-0.19 ; 0.01)$ & \\
\hline
\end{tabular}

The 2004 Pelotas Birth Cohort Study, Brazil

${ }^{a}$ Adjusted for: socioeconomic position, number of children at the time of birth, maternal age at birth, maternal education, smoking during pregnancy, child's sex and skin colour, birth weight, exclusive breastfeeding duration, and number of meals per day

${ }^{\mathrm{b}}$ Adjusted for: socioeconomic position, number of children at the time of birth, maternal age at birth, maternal education, smoking during pregnancy, child's sex and skin colour, birth weight, exclusive breastfeeding duration, number of meals per day, and similar-labeled component at 1 year

${ }^{\mathrm{c}}$ Adjusted for: socioeconomic position, number of children at the time of birth, maternal age at birth, maternal education, smoking during pregnancy, child's sex and skin colour, birth weight, exclusive breastfeeding duration, number of meals per day, and similar-labeled component at 1 and 2 years

with higher trunk fat mass and with lower gynoid fat mass at 6 years. Furthermore, high score on snacks, characterized by high adherence to coffee, bread and cookies, appeared to be associated with lower BMI, but higher gynoid fat mass percentage at 6 years.

Interpretation of results for BMI $z$-score is easier, as BMI is a valuable adiposity marker for diseases and mortality risks, and is widely used in clinical and epidemiological studies [32, 33]. Greater caution is needed when interpreting the results for the novel body shape component "corpulence", since its utility in predicting future adverse outcomes is not known. However, as corpulence is very highly correlated with BMI and other adiposity measures $(r>0.9)$ [20], and results for this component followed a similar trend that those for BMI, we can presume that interpretation for this body shape component goes in the same direction as for BMI.

In addition, we conducted further analyses using regional measures of body shape from DXA (trunk and gynoid fat mass percentage) to help in interpreting results for body shape. In these analyses, we have seen that high score on snacks at 4 years predicted higher proportion of gynoid fat mass at 6 years, while high score on staple at 2 years predicted higher proportion of trunk fat mass and lower proportion of gynoid fat mass. The previous epidemiological and mechanistic studies have demonstrated that higher proportion of fat mass in central area increases risk of adverse outcomes, while peripheral fat is beneficial for metabolic disorders [34-38], and our results may be indicating that lower adherence to rice and beans at 2 years, and high adherence to coffee, bread, and cookies at 4 years could be beneficial to body shape at 6 years, decreasing the overall body size, and improving the distribution of body fat.

However, what might be the reason for high adherence to snacks at 4 years promotes lower BMI and better body shape? Higher scores on snacks might be associated with some factors, such as age of introduction of foods, food availability at household, or quality of diet, for example, 


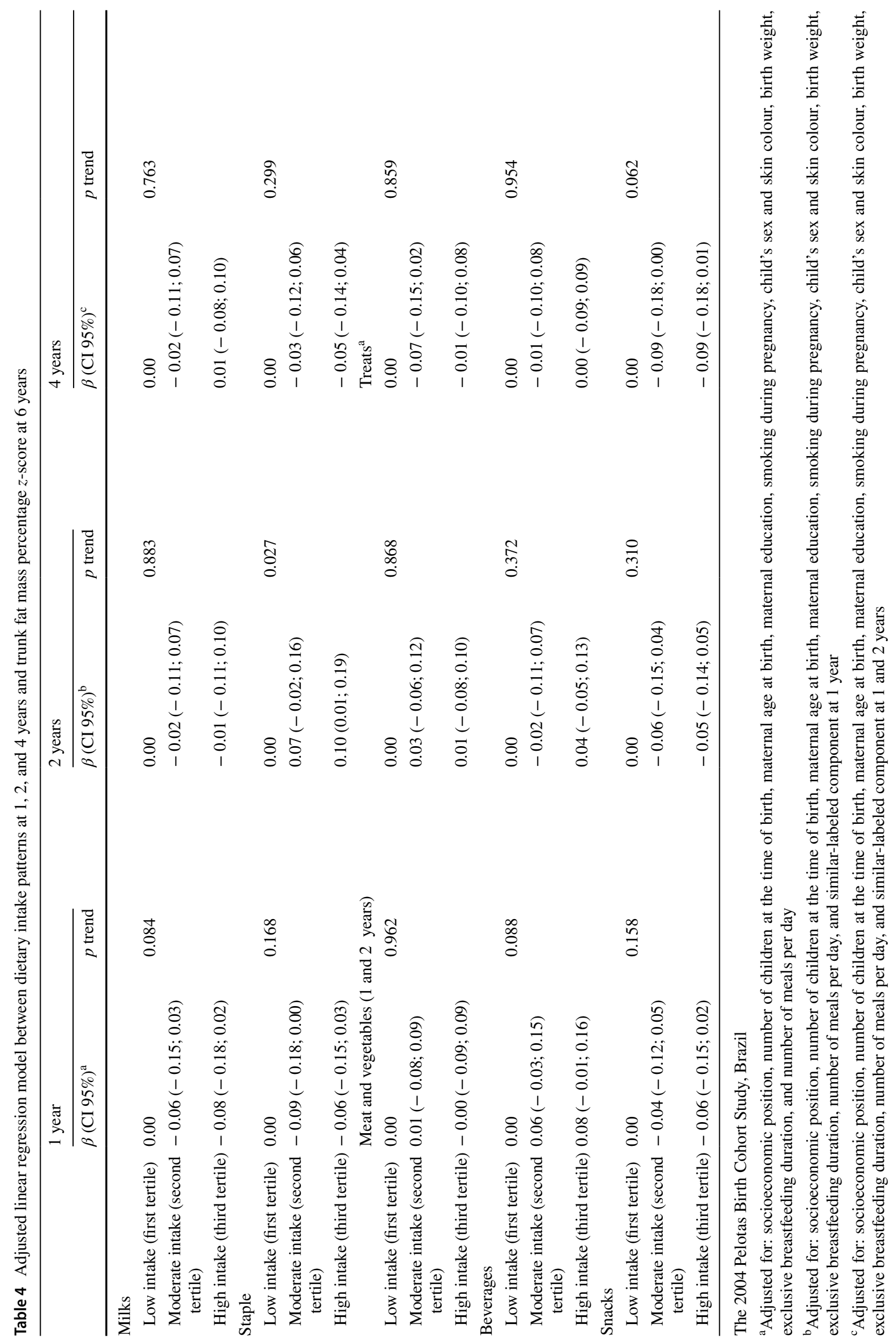




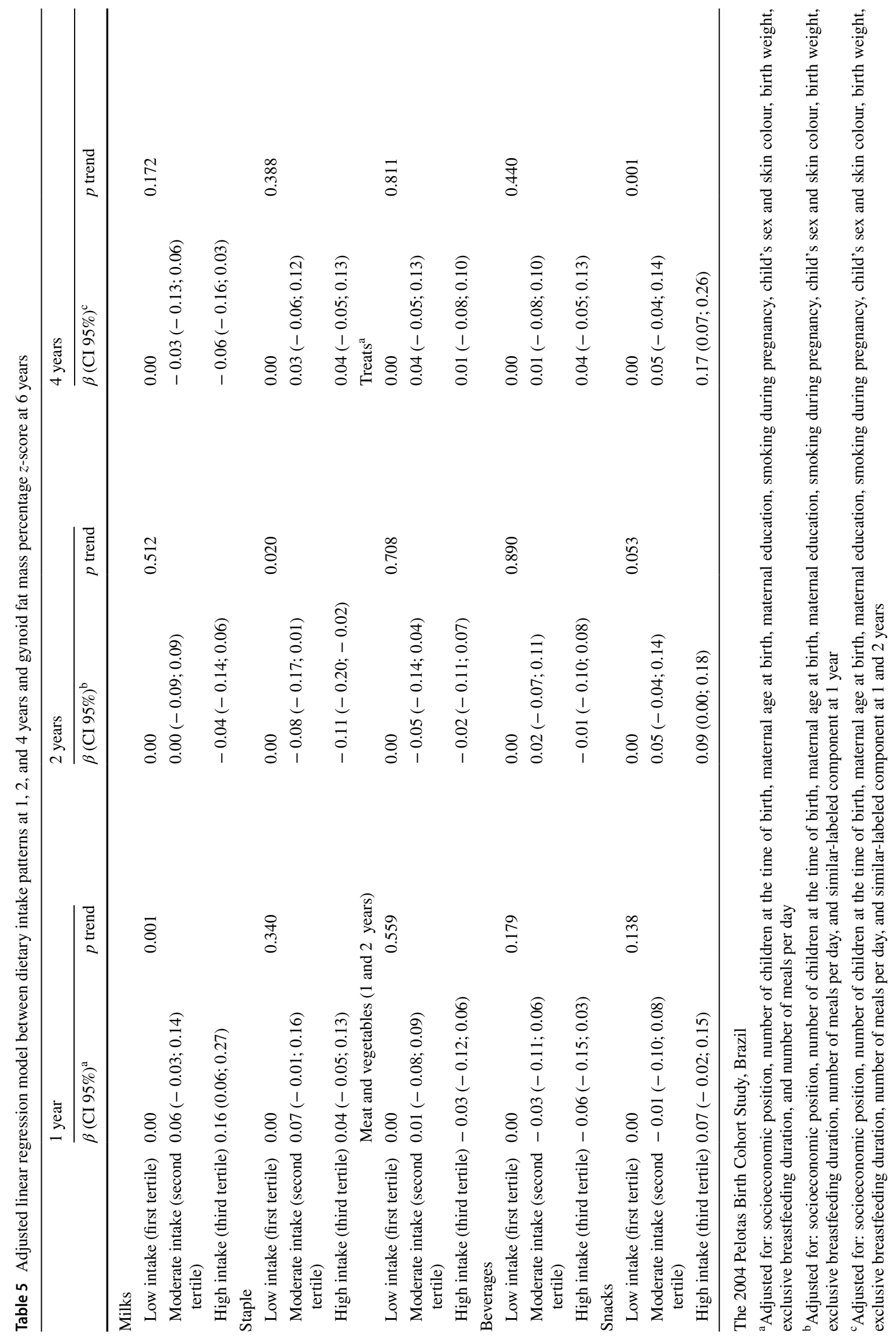


which may interfere on BMI and body shape of these children. However, to support this hypothesis, additional studies focusing not solely on dietary patterns but also on other aspects of feeding habits are needed to better understand the role of early feeding habits, especially of snacks adherence, on BMI and distribution of body fat in childhood.

Nevertheless, we cannot reject the hypothesis of residual confounding by other socioeconomic or demographic factors not included in the adjusted model, since the observed effect sizes of the associations were small (at best, $\beta=0.20$ $z$-score), despite $p$ values $<0.05$. Moreover, we also evidenced a considerable reduction in estimated effects for all outcomes included in our analyses ( $>40 \%$ ) after adjustment for potential confounders. The published reports from this cohort and other studies have already showed that dietary intake patterns are highly associated with socioeconomic and demographic characteristics [21, 28, 39]. Finally, since many associations were tested here, we also must be aware about the multiple testing problem, which might increase the probability of type I error in the associations investigated [40]. Nonetheless, the good power of our sample helps to address this issue.

Another notable finding of our study was the association between the component labeled milks at 1 year and body shape measures from DXA. High adherence to milks at 1 year (characterized by high adherence to breast milk) predicted higher gynoid fat mass at 6 years. This result may indicate a possible benefit of breast milk for body shape. The role of breastfeeding on obesity status in childhood remains debated [41]. Unfortunately, here, we did not address the effects of breastfeeding duration on body shape, and future investigations would be interesting to look at the role of exclusive and total breastfeeding duration on obesity status and body shape as well as the mechanism involved in this relationship.

A strength of our study is the repeated assessment of food intake, allowing specific descriptions of dietary patterns during infancy and early childhood. The high retention rates (above 90\%) in all follow-ups as well as regular data collection are important to minimize biases. Outcome assessment is a further strength, as our study did not focus solely on BMI, but used a novel consideration of body size and body shape that reflects adiposity and fat distribution added by regional fat mass measures from DXA.

Limitations include the assessment of food intake by 24-h recall reported by mothers, which may not reflect children's regular feeding habits. This indirect measure can result in measurement error, since mothers can overestimate total energy intake of children [42]. In addition, the questionnaires used in 1-, 2-, and 4-year-old follow-ups did not allow us to quantify food amounts and the dietary intake patterns described in these three age-points do not reflect overall dietary quality. Finally, we were not able to employ the full strength of longitudinal analyses in our study, since we have run separate linear regression models by each agepoint. We performed analyses separately by each age-point due to the variation in food item loadings of components with the same label as well as the weak inter-correlations between components.

In conclusion, our study adds evidence that the consumption of dietary patterns in the early life presents inconsistent association with BMI and body shape at 6 years, as all the effects seen here were attenuated by adjustment for socioeconomic and demographic characteristics. However, lower adherence to staple at 2 years and high adherence to snacks at 4 years may promote a better body shape, with lower BMI and central fat and higher proportion of gynoid fat mass.

Acknowledgements We are thankful for all cohort members and their mothers/legal guardians for have accepted and contributed with this follow-up.

Author contributions This study was conducted by LPS, KKO, and AJDB. LPS performed the analyses and drafted the manuscript. KKO proposed the idea, supervised the analyses, and helped in drafting the manuscript. AJDB contributed in the statistical analyses and helped in drafting the manuscript. AJDB, AM, and ISS participated in the design and conduction of the original cohort study as well as in interpreting results and reviewing the manuscript. All authors read and approved the final version.

Funding The 2004 birth cohort study is supported by the Wellcome Trust through the scheme called 'Major Awards for Latin America on Health Consequences of Population Change' (Grant number 086974/Z/08/Z). The World Health Organization (Grant number 03014HNI), Brazilian National Research Council (CNPq) (Grant numbers 481012-2009-5; 484077-2010-4; 470965-2010-0; and 481141-2007-3), and Brazilian Ministry of Health (Grant number 25000.105293/2004-83) have supported the previous phase of the study. LPS was supported by 'Science without Borders' Brazilian scheme under the protocol number 201801/2014-0.

\section{Compliance with ethical standards}

Conflict of interest All authors declare that they have no competing interests.

Open Access This article is distributed under the terms of the Creative Commons Attribution 4.0 International License (http://creativeco mmons.org/licenses/by/4.0/), which permits unrestricted use, distribution, and reproduction in any medium, provided you give appropriate credit to the original author(s) and the source, provide a link to the Creative Commons license, and indicate if changes were made.

\section{References}

1. Popkin B, Adair L, Ng S (2012) Global nutrition transition and the pandemic of obesity in developing countries. Nutr Rev 70(1):3-21

2. Bermudez O, Tucker K (2003) Trends in dietary patterns of Latin American populations. Cad Saude Publica 19(1):S87-S99

3. Popkin B (2001) The nutrition transition and obesity in the developing world. J Nutr 131:871S-873S 
4. Rivera J, Cassío T, Pedraza L, Aburto T, Sánchez T, Martorell R (2014) Childhood and adolescent overweight and obesity in Latin America: a systematic review. Lancet Diabetes Endocrinol 2:321-332

5. Brasil (2010) Pesquisa de Orçamentos Familiares 2008-2009: antropometria e estado nutricional de crianças, adolescentes e adutlos no Brasil. Instituto Brasileiro de Geografia e Estatística, Brasília

6. Jennings A, Welch A, van Sluijs E, Griffin S, Cassidy A (2011) Diet quality is independently associated with weight status in children aged 9-10 years. J Nutr 141:453-459

7. O'Connor L, Brage S, Griffin S, Wareham N, Forouhi N (2015) The cross-sectional association between snacking behaviour and measures of adiposity: the Fenland Study, UK. Br J Nutr 114(8):1286-1293

8. Hu F (2002) Dietary patterns analysis: a new direction in nutritional epidemiology. Curr Opin Lipidol 13:3-9

9. Varraso R, Garcia-Aymerich J, Monier F (2012) Assessment of dietary patterns in nutritional epidemiology: principal components analysis compared with confirmatory factor analysis. Am J Clin Nutrition 96:1079-1092

10. Mikkila V, Rasanen L, Raitakari O, Pietinen P, Viikari J (2005) Consistent dietary patterns identified from childhood to adulthood: the Cardiovascular Risk in Young Finns Study. Br J Nutr 93(6):923-931

11. Northstone K, Emmett P (2008) Are dietary patterns stable throughout early and mid-childhood? A birth cohort study. Br J Nutr 100(5):1069-1076

12. Lioret S, Betoko A, Forhan A, Charles M, Heude B, LauzonGuillain B (2015) Dietary patterns track from infancy to preschool age: cross-sectional and longitudinal perspectives. J Nutr 145(4):775-782

13. Cutler G, Flood A, Hannan P, Slavin J, Neumark-Sztainer D (2012) Association between major patterns of dietary intake and weight status in adolescents. Br J Nutr 108:349-356

14. Shroff M, Perng W, Baylin A, Mora-Plazas M, Marin C, Villamor E (2013) Adherence to a snacking dietary pattern and soda intake are related to the development of adiposity: a prospective study in school-age children. Public Health Nutr 17(7):1507-1513

15. Pala V, Lissner L, Hebestreit A, Lanfer A, Sieri S, Siani A, Huybrechts I, Kambek L, Molnar D, Tornaritis M, Moreno L, Ahrens W, Krogh V (2013) Dietary patterns and longitudinal change in body mass in European children: a follow-up study on the IDEFICS multicenter cohort. Eur J Clin Nutr 67:1042-1049

16. Fields D, Goran M, McCrory M (2002) Body-composition assessment via air-displacement plethysmography in adults and children: a review. Am J Clin Nutr 75:453-467

17. Wells J, Haroun D, Williams J, Wilson C, Darch T, Viner R, Eaton S, Fewtrell M (2010) Evaluation of DXA against the four-component model of body composition in obese children and adolescents aged 5-21 years. Int J Obes 34(4):649-655

18. Wang J, Gallagher D, Thornton J, Yu W, Horlick M, Pi-Sunyer $X$ (2006) Validation of a 3-dimensional photonic scanner for the measurement of body volumes, dimensions, and percentage of body fat. Am J Clin Nutr 83:809-816

19. Wells J, Stocks J, Bonner R, Raywood E, Legg S, Lee S, Treleaven $P$, Lum S (2015) Acceptability, precision and accuracy of 3D photonic scanning for measurement of body shape in a multi-ethnic sample of children aged 5-11 years: the SLIC study. PLoS One 10(4): $\mathrm{e} 0124193$

20. Santos L, Ong K, Day F, Wells J, Matijasevich A, Santos I, Victora C, Barros A (2016) Body shape and size in 6-year old children: assessment by three-dimensional photonic scanning. Int $\mathrm{J}$ Obes 40(6):1012-1017

21. Gatica G, Barros AJ, Madruga S, Matijasevich A, Santos IS (2012) Food intake profiles of children aged 12, 24 and 48 months from the 2004 Pelotas (Brazil) birth cohort: an exploratory analysis using principal components. Int J Behav Nutr Phys Act 9:43. https://doi.org/10.1186/1479-5868-9-43

22. Barros AJD, Santos IS, Victora CG, Albernaz EP, Domingues MR, Timm IK, Matijasevich A, Bertoldi AD, Barros FC (2006) The 2004 Pelotas birth cohort: methods and description. Rev Saude Publ 40(3):402-413

23. Santos IS, Barros AJ, Matijasevich A, Zanini R, Chrestani Cesar MA, Camargo-Figuera FA, Oliveira IO, Barros FC, Victora CG (2014) Cohort profile update: 2004 Pelotas (Brazil) Birth Cohort Study. Body composition, mental health and genetic assessment at the 6 years follow-up. Int J Epidemiol 43(5):1437-1437. https ://doi.org/10.1093/ije/dyu144

24. Araujo CL, Albernaz EP, Tomasi E, Victora CG (2004) Implementation of the WHO Multicentre Growth Reference Study in Brazil. Food Nutr Bull 25(1):S53-S58

25. de Onis M (2007) Development of a WHO growth reference for school-aged children and adolescents. Bull World Health Organ 85(09):660-667. https://doi.org/10.2471/blt.07.043497

26. Habitch JP (1974) Standardization of quantitative epidemiological methods in the field. Bol Of Sanit Panam 76(5):375-384

27. Barros AJD, Victora CG (2005) A nationwide wealth score based on the 2000 Brazilian demographic census. Rev Saude Publ 39(4):523-529

28. Craig L, McNeill G, Macdiarmid J, Masson L, Holmes B (2010) Dietary patterns of school-age children in Scotland: association with socio-economic indicators, physical activity and obesity. $\mathrm{Br}$ J Nutr 103:319-334

29. Smith A, Emmett P, Newby P, Northstone K (2014) Dietary patterns and changes in body composition in children between 9 and 11 years. Food Nutr Res. https://doi.org/10.3402/fnr.v58.22769

30. Robinson SM, Marriott LD, Crozier SR, Harvey NC, Gale CR, Inskip HM, Baird J, Law CM, Godfrey KM, Cooper C (2009) Variations in infant feeding practice are associated with body composition in childhood: a prospective cohort study. J Clin Endocrinol Metab 94(8):2799-2805. https://doi.org/10.1210/jc.2009-0030

31. Voortman T, Leermakers ET, Franco OH, Jaddoe VW, Moll HA, Hofman A, van den Hooven EH, Kiefte-de Jong JC (2016) A priori and a posteriori dietary patterns at the age of 1 year and body composition at the age of 6 years: the Generation R Study. Eur J Epidemiol 31(8):775-783. https://doi.org/10.1007/s1065 4-016-0179-x

32. Pietrobeli A, Faith M, Allison D, Gallagher D, Chiumello G, Heymsfield S (1998) Body mass index as a measure of adiposity among children and adolescents: a validation study. J Pediatr 132(2):204-210

33. Lindsay R, Hanson R, Roumain J, Ravussin E, Knowler W, Tataranni $P$ (2001) Body mass index as a measure of adiposity in children and adolescentes: relationship to adiposity by dual energy $\mathrm{X}$-ray absorptiometry and to cardiovascular risk factors. J Clin End Metabol 86(9):4061-4067

34. Snijder M, Dekker J, Visser M, Bouter L, Stehouwer C, Yudkin J, Heine J, Nijpels G, Seidell J (2004) Trunk fat and leg fat have independent and opposite associations with fasting and postload glucose levels. Diabetes Care 27(2):372-377

35. Snijder M, Visser M, Dekker J, Goodpaster B, Harris T, Kritchevsky S, De Rekeneire N, Kanaya A, Newman A, Tylavsky F, Seidell J (2005) Low subcutaneous thigh fat is a risk factor for unfavourable glucose and lipid levels, independent of high abdominal fat. Diabetologia 48(2):301-308

36. Yang M, Lin J, Ma X, Zhu C, Wei C, Wang L, Jiao J, Zhu S (2016) Truncal and leg fat associations with metabolic risk factors among Chinese adults. Asia Pac J Clin Nutr 25(4):798-809. https://doi. org/10.6133/apjen.092015.35

37. Cerhan JR, Moore SC, Jacobs EJ, Kitahara CM, Rosenberg PS, Adami HO, Ebbert JO, English DR, Gapstur SM, Giles GG, 
Horn-Ross PL, Park Y, Patel AV, Robien K, Weiderpass E, Willett WC, Wolk A, Zeleniuch-Jacquotte A, Hartge P, Bernstein L, Berrington de Gonzalez A (2014) A pooled analysis of waist circumference and mortality in 650,000 adults. Mayo Clin Proc 89(3):335-345. https://doi.org/10.1016/j.mayocp.2013.11.011

38. Lotta L, Gulati P, Day F, Payne F, Ongen H, de Bunt M, Gaulton K, Eicher J, Sharp S, Luan J, Rolfe E, Stewart I, Wheeler E, Willems S, Adams C, Yaghootkar H, Forouhi N, Khaw K, Johnson A, Semple R, Frayling T, Perry J, Dermitzakis E, McCarthy M, Barroso I, Wareham N, Savage D, Lengenberg C, O'Rahilly S, Scott R (2017) Integrative genomic analysis implicates limited peripheral adipose storage capacity in the pathogenesis of human insuline resistance. Nat Genet 49(2):17-25

39. Santos LP, Assuncao MC, Matijasevich A, Santos IS, Barros AJ (2016) Dietary intake patterns of children aged 6 years and their association with socioeconomic and demographic characteristics, early feeding practices and body mass index. BMC Public Health 16(1):1055. https://doi.org/10.1186/s 1288 9-016-3725-2

40. Sainani KL (2009) The problem of multiple testing. PM R 1(12):1098-1103. https://doi.org/10.1016/j.pmrj.2009.10.004

41. Lefebvre C, John R (2014) The effect of breastfeeding on childhood overweight and obesity: a systematic review of literature. J Am Assoc Nurse Pract 26(7):386-401

42. Burrows T, Truby H, Morgan P, Callister R, Davies P, Collins C (2013) A comparison and validation of child versus parent reporting of children's energy intake using food frequency questionnaire versus food records: who's an accurate reporter? Clin Nutr 32(4):613-618 